\title{
Updated texts on medical ethics
}

SUNIL K PANDYA

Rimpi Gupta, Editor: C M Francis, Medical Ethics as per revised $\mathrm{MCl}$ curriculum. $4^{\text {th }}$ edition. New Delhi: Jaypee Brothers Medical Publishers (P) Ltd; 2020, pp 220, Rs 295 (paperback), ISBN 978-93-89188-62-2.

Olinda Timms, Biomedical Ethics AETCOM companion for medical students. $2^{\text {nd }}$ edition. New Delhi: Elsevier - RELX India Pvt. Ltd; 2019. 284 pp, Rs 450 (paperback), ISBN 97881-312-5965-8.

As the two books under review are new editions of earlier works modified to incorporate the AETCOM guidelines, a brief note on AETCOM may be useful.

\section{AETCOM}

In 2018, the Medical Council of India issued its 85-page volume entitled Attitude, ethics and communication with the acronym AETCOM. Dr Jayshree Mehta, President of the Council termed this a "competency based curriculum that has been proposed by the Medical Council of India (that) would definitely serve a larger cause in the domain of quality centricity." In the next paragraph, we learn that "The Conative domain which hitherto was not appropriately incorporated and structured in the curriculum has been specifically dispensed of by providing a definitive model for the same titled AETCOM - Attitude, Ethics and Communication Model." She expressed the hope that this curriculum "would go a long way in creating an Indian Medical Graduate to realistically turn out to be an International Medical Graduate capable of catering to the cause and requirement of health care delivery across the boundaries all over the Globe."

She was appreciative of Dr Vedprakash Mishra, chairman of the academic team that produced this document.

In his foreword, Dr Mishra tells us that "Health Professions and practice is a complex interplay of Knowledge, Clinical Skills \& Acumen, Communication, Attitude, Inter-Professional behavior and is largely dependent on strong Ethical values." He sums up the purpose of the curriculum thus: "The entire concept of AETCOM module lies on the fundamental principle that changing a person's attitude can change his or her behavior. The Cognitive components of attitudes are more fundamental and constant over time and more closely connected to basic values."

\footnotetext{
Author: Sunil K Pandya (shunil3@gmail.com), Department of Neurosurgery Jaslok Hospital and Research Centre, Deshmukh Marg, Mumbai 400026 INDIA

To cite: Pandya SK. Updated texts on medical ethics. Indian J Med Ethics.2020 Jan-Mar; 5(1) NS: 76-9. DOI: 10.20529/IJME.2019.080.

Published online on December 21, 2019.

Manuscript Editor: Sanjay A Pai

CIndian Journal of Medical Ethics 2019
}

There is much more along these lines in the segment preceding the document itself.

A "hybrid PBL model" was suggested as "one of the most effective ways for students to explore the various facets of real life issues that will confront them in their careers."

Case discussions, assessment of skills related to attitude, ethics, communication and learning modules for each professional year follow. Queries such as: What does it mean to be a doctor?, What does it mean to be a patient?, and topics such as the doctor-patient relationship, the foundations of communication, the cadaver as the first teacher of the medical student, the foundations of bioethics etc, are dealt with.

\section{Rimpi Gupta, Editor: C M Francis, Medical ethics as per revised $\mathrm{MCl}$ curriculum.}

Dr CM Francis, author of the original work Medical ethics, also wrote on HIV, law and ethics; conflicts and confluence - ancient and modern medical ethics in India; hospital administration and health policy of the church in India. Educated in medicine at the Madras Medical College, he studied physiology in Cambridge, England and headed the department of Physiology at St. Johns Medical College in Bangalore. He later served as the Dean of this institute. The tribute paid to him (1) and the obituary by Dr Ravi D'Souza (2) in this journal deserve study.

Dr Rimpi Gupta is an Assistant Professor in the department of Anatomy at Kalpana Chawla Government Medical College, Karnal, Haryana. She is also the nodal officer of the body donation programme of her institution. Her key area of interest is Anatomy. I was unable to find papers on medical ethics by her.

The first three editions of the book under review were brought out by Dr Francis in 1993, 2004 and 2008. The first edition was reviewed in this journal by Dr Amar Jesani (3).

Dr Rimpi makes her appearance with this 4th edition. She has reproduced Dr Francis' preface to the first edition and added one of her own.

Since I have access to the second edition, I shall attempt to compare its contents with those of the volume under review.

Whilst Chapter 1 remains almost unchanged, we see changes from Chapter 2 onwards. Brief notes have been introduced in some chapters to bring in the concepts highlighted in the AETCOM document.

Some chapters have been realigned. Chapters 7 (autonomy and informed consent) and 8 (rights of patients) in the second edition are now chapters 6 and 7 .

Most of Dr Francis' text has been reproduced verbatim. Even errors are reproduced as in the original text, for example: "The 
geneal assembly..." on page 39 of the $2^{\text {nd }}$ edition and on page 36 of the $4^{\text {th }}$ edition.

Little attempt has been made to update information. As in 2004 ( $2^{\text {nd }}$ edition, page 76), so in 2019 (page 71), we read: "The new Indian Medical Council (professional conduct, etiquette and ethcis) Regulations 2002 are more explicit:" The spelling mistake "ethcis" is also reproduced verbatim.

We continue to read of "ICMR guidelines proposed" and the report on these proposed guidelines from The Times of India dated September 2002 (pages 82-83 in the $4^{\text {th }}$ edition). The draft Assisted Reproductive Technology (Regulation) Bill, 2010, finds no mention. We also do not find any mention of The Surrogacy (Regulation) Bill, 2019, or the recent debates on commercial surrogacy or on post-mortem retrieval of sperm for assisted reproduction.

Chapter 12 deals with care of the terminally ill in both the $2^{\text {nd }}$ and $4^{\text {th }}$ editions. I could not find any significant differences in the two versions except on page 95 of the present edition where there is a reference to Aruna Shanbaug and the permission granted by the Supreme Court of India in 2018 to withdraw life support in specified instances. However, though this Court did allow us to draw up living wills, we continue to read "The living will is not legal here and not binding on the doctors" ( $p$ 92) as we did on page 99 in the $2^{\text {nd }}$ edition.

Suicide is termed a crime in Chapter 13 ( $p 102$ of edition 4, as on $p 111$ in edition 2). There is no reference to the passage of The Mental Healthcare Bill of 2016 that decriminalised suicide and provided for mental healthcare and services for persons with mental illness.

As we turn to Chapter 22 (Clinical Trials) towards the end of the book, we see, once again, reproduction of the text from the second edition without any attempt at providing up to date information. Whilst the chapter continues to refer to guidelines published in 1996 and the Declaration of Helsinki in 2001, there is no reference to, or details from, such documents as the National Ethical Guidelines for Biomedical and Health Research Involving Human Participants, published by ICMR in 2017, or later documents.

Whilst some references are provided in the text, there is no list of references at the end of each chapter or at the end of the volume. None of the references are provided as recommended by the International Committee of Medical Journal Editors.

The Annexure does contain the text of the regulations of the Medical Council of India updated to October 2018 (as against March 2002 in edition 2).

Dr Rimpi Gupta has lost a golden opportunity. She could have updated Dr Francis' book to advantage, not only to incorporate the schedules suggested in the AETCOM guidelines but also to correct errors and include the significant amount of new information that is relevant to India since the publication of editions 2 and 3, and now freely available in documents. The reliance on articles in foreign publications could have been improved upon by replacing many of them with texts in numerous books from and on India, and journals such as the Indian Journal of Medical Ethics and publications by the Medico Friends Circle. The experiences of non-governmental organisations working for the welfare of the poor, the downtrodden and tribal communities provide ample material that could have been used to enthuse medical students.

It is also important to remind students of what medicine can and cannot achieve, the difficulties in treating patients and staying true to medical ethics in the current milieu and the need to strive towards high ideals despite the odds against them.

\section{References}

1. Felicitations. Dr CM Francis. Indian J Med Ethics. 2007 [cited 2019 Dec 11]; 7(Supplement Book): p S-13. Available from:https://ijme.in/nbc20140321/pdf/nbc2/NBC-2007-conference-supplement-issue.pdf

2. D'Souza R. Obituary: Dr CM Francis. Indian J Med Ethics. 2009 Jul-Sep [cited 2019 Dec 3]; 6(3):168. Available from: http://ijme.in/articles/dr-c$\mathrm{m}$-francis/?galley=html

3. Jesani A. Book Review: Medical Ethics. Indian J Med Ethics.1994 MayJun [cited 2019 Dec 3]; 2(2): 8. Available from: https://ijme.in/articles/ medical-ethics/?galley $=$ html

\section{Olinda Timms, Biomedical Ethics AETCOM companion for medical students. $2^{\text {nd }}$ edition.}

I had reviewed the first edition of this book in this journal (1). In that review I had provided some background information on DrTimms.

The preface to the $2^{\text {nd }}$ edition points out, that in addition to the AETCOM modules, there is scope for providing background reading material and content for faculty and students.

This book proceeds to do that and also provides case studies and resource material.

Excerpts from the works of such pioneers as Charaka (this is the spelling used in this book), Susruta and Kashyapa are accompanied by commentaries on what we can continue to learn from ancient Indian medicine. Excerpts and quotations from leaders of thought elsewhere in the world are also provided at appropriate places.

The original format has fortunately been retained. Each chapter is divided into sections. Chapter 1 entitled "Introduction to medical ethics" has the following sections: "Why do we need medical ethics?", "Who is a professional?", "History of medical ethics", and "Indian tradition in medical ethics: a legacy".

A quotation that stimulates thought leads to an outline of the chapter that follows and what it aims to achieve as learning objectives. The case study provided at the start of each chapter is left unanswered at the end of the chapter but pointed questions are posed so that using the information provided in the chapter the student can proceed to formulate a solution to the dilemma highlighted in the case study.

The reader is also encouraged to put on the thinking cap in other ways. Discussing whether ethics and morality in general 
can be absolute, we are given the example: Killing another human may be considered morally wrong; however, killing another human in battle may not.

Relatively uncommon topics are explained fluently. The theories of morality are an example. As physicians untrained in formal philosophy, we balk at terms such as "Virtue ethics", "deontology" and "teleology". The text on pages 20-23 will put us at ease and enable the usage of these and other terms with confidence. Likewise, the principles of medical ethics (pp 2327) provide definitions, quotations from individuals as varied as Hippocrates and John Rawls, agencies formulating codes of ethics and references for further study in addition to the usual explanatory notes.

Short summaries of important landmarks in medical ethics are to be found throughout the book. Chapter 6 ("Ethics at the end of life"), for instance, has notes on Dr Jack Kevorkian (called Dr Death as he promoted euthanasia); Dr Nigel Cox (who caused the death of an elderly woman in 1992 to relieve her of pain from crippling rheumatoid arthritis); the case of Terri Schiavo (whose persistent vegetative state led to a right to die case); and that of Aruna Shanbaug at the KEM. Hospital in Mumbai. In each boxed note, references are provided for further study. This chapter also provides information on the philosophy of euthanasia and death in Hinduism, Buddhism, Sikhism, Islam, and Christianity. The discussion on the pros and cons of euthanasia includes a discussion of the slippery slope that led to the Nazi atrocities.

There is much to stimulate young minds. Let me quote from the section "Who is a professional?" in Chapter 1:

There can be differing perceptions of a medical career, depending on our personal goals and values:

- Medical practice as an occupation: We could consider our medical work as a means to be gainfully occupied and earn a living. At this level, the practice of medicine is merely an occupation like any other: engineering, fashion design, or flight pilot.

- Medical practice as a profession: The next level would be medical practice as a profession where we attribute social significance to our work and its impact on human life. There is also adherence to the standard of conduct expected by the peer group.

- Medical practice as a vocation: At the highest level, the chosen career is a vocation. It is a life calling, expressed by the highest level of commitment and dedication. Doctors who dedicate their life to medical practice at remote locations or who work under challenging conditions are examples that would fall into this category.

Not every doctor may consider medical practice as a vocation, although some of the best doctors of all time have been driven by passion for their work and service to others. However, it is expected that every graduate will practice medicine as a profession. Anything less will undermine the traditional respect accorded to doctors and their work in society.'
There can be no quarrel with the sentences in the last paragraph. (Incidentally, interested readers may also benefit from Justice Tuttle's stirring definition of a professional. ${ }^{1}$ )

New terms are defined wherever they are used for the first time. Here is an example:

Bioethics is a newer term, first coined by Fritz Jahr in 1927 but popularized by the American biochemist V.R. Potter since 1971. The definition by Warren Reich in 1995 was "the systematic study of the moral dimensions-including moral vision, decisions, conduct and policies-of life sciences and healthcare, employing a variety of ethical methodologies in an interdisciplinary setting.

I learnt a new term on page 21: Universalizability, which, as Dr. Timms explains, was used by Immanuel Kant (1724-1804), the influential German philosopher. The dictionary tells me that this term, used as a noun in ethics, enunciates the principle that the only morally acceptable maxims of our actions are those that could rationally be willed to be universal law.

Academics and researchers, in particular, must study Chapter 13 on Publication ethics. The quotation at the beginning of this section is from Dr Edmund Pellegrino (1920-2013): "Many of our habits as physicians and what we consider good medicine are traceable to imitation or rejection of some teacher's example." It is especially apt as the case study that follows pertains to the all-too-familiar demand by the head of the department that his name be included as an author in a paper or chapter to be published, even though he had played no role in the work being described.

A list of references is provided at the end of each chapter. Appendix $C$ contains additional references listed against each chapter as suggested reading. These are different from those provided at the end of the relevant chapter. The references to Chapter 1 in this appendix date from 1803 to 2015; whilst those at the end of Chapter 1 date from 1949 to 2011. Where available, links are provided for access to references on the internet.

Appendix $D$ also provides lists of relevant movies, between three and 14 movies being listed against each chapter. These movies date from 1939 (Dark Victory) to 2013. Western films and those from India are included. Access to the movies is not provided and the reader must seek them elsewhere. Doubtless, you will have your own preferences. Should you know of important films not included here, could you write to this journal, providing details? This will benefit other readers.

Appendix B deals with the practical implementation of the AETCOM approach and provides answers to such questions as: How can medical ethics be included seamlessly in the curriculum without needing additional teaching hours?; Who will teach ethics?; What should be taught?; Practical tips to avoid disconnecting ethics from clinical practice and make the former come alive as part of teaching in clinics and wards are provided. A detailed list of suggestions for enabling these is to be found on pages $266-269$ and includes such subheads 
as: preclinical years, various subjects (Anatomy, Physiology, etc); Clinical years, Forensic Medicine and Community Health Medicine. Under Obstetrics and Gynaecology; for example, we have topics such as Ethical issues related to abortion, the Medical Termination of Pregnancy Act, sterilisation camps, assisted reproduction techniques, ethical issues with surrogacy, prenatal diagnostic tests and the PCPNDT Act. The section also offers suggestions on how students' comprehension of what has been conveyed can be assessed. The references at the end of this chapter include papers on teaching medical ethics by experts such as Dr Edmund Pellegrino.

I was sorry to see some eminences referred to in the text missing from the index. Sir William Osler (referred to in the text on $\mathrm{p} \mathrm{21}$ ) has been excluded. He was an exemplar of ethical medical practice and taught it effectively. He is in good company, though, for Aristotle and Plato (referred to on p 20) also fail to find mention in the index.
Purchasers of the book are provided access to the online edition of the book. Once one has registered, access to the full text of the book and its various sections is easy. Notes can be added to any section and relevant text can be highlighted with one of five colours. Unfortunately, the search facility is primitive and not very helpful.

There is much in common with Dr Francis' book as regards contents in the two editions. In Dr Timms' book, I could not help wishing that the lists of references and of films had been brought up to date.

\section{${ }^{1}$ Note}

See: Elson C M: Remembering Judge Elbert Tuttle. Sr. Cornell Law Review 1996;82: 15-18.

\section{References}

4. Pandya SK. At last - a home grown ethics text! Indian J Med Ethics. 2016 Oct-Dec;1(4)NS: 256-7.DOI: https://doi.org/10.20529/IJME.2016.072.

\section{Article 15: truth or fiction?}

\section{MEGHNA ARUNACHALAM}

Article 15, Producer Anubhav Sinha, Zee Studios; Director Anubhav Sinha. Hindi, 130 minutes. 2019.

Article 15 of the Indian Constitution (1) states that, "The State shall not discriminate against any citizen on grounds only of religion, race, caste, sex, place of birth or any of them; No citizen shall, on grounds only of religion, race, caste, sex, place of birth or any of them, be subject to any disability, liability, restriction or condition with regard to (a) access to shops, public restaurants, hotels, and places of public entertainment or (b) the use of wells, tanks, bathing ghats, roads, and places of public resort maintained wholly or partly out of State funds or dedicated to the use of the general public".

It has been 69 years since our constitution came into force, and yet we require hard-hitting movies, like Article 15, to remind us of the glaring inequalities in our country. The movie is a story of the rape and murder of two minor Dalit girls and the hunt for a third missing girl, with the ensuing investigation. However, even more so, it is a story of casteism and power play. Everyday scenes in the movie bring home the realities of casteism that are so prevalent in India. The scenes where the police refuse to

Author: Meghna Arunachalam (meghnaarunachalam@yenepoya.edu. in), MSc (Research Ethics) scholar, YU-FIC Research Ethics Master's Program for India, Yenepoya University and Hospital, Derlakatte, Mangalore 575022 INDIA.

To cite: Arunachalam M. Article 15: Truth or fiction? Indian J Med Ethics. 2020 Jan-Mar;5(1) NS: 79-80. DOI:10.20529/IJME.2020.023.

CIndian Journal of Medical Ethics, 2020 buy water from a village shop because it is owned by a Dalit, or where the fathers of the murdered young girls drink water using their hands, because their caste does not permit them to drink water from a glass before people from a higher caste, or where some Dalits are lynched for daring to enter a temple, or where a man gets into a manhole naked to clear the night soil blocking it, bring to mind the live customs of a medieval India.

The movie is subtle, even in the hard-hitting scenes. All the actors, from Ayushmann Khurrana as the protagonist to Eza Sumbul Touqeer as the housekeeper/cook, delivered commendable performances. The movie is well-directed and without melodrama and hyperbole. The protagonist, a young police officer, ASP Ayan Ranjan, a Brahmin educated at St Stephen's, Delhi, is bewildered as he observes casteism at all levels, including in his police station in Lalgaon, where the behaviour of all the police personnel is coloured by the observance of caste. Casteism is so deep-rooted in India that it is accepted as a necessity for social functioning and a justification for discrimination. A dialogue in the movie, "Hum kabhi Harijan ho jaate hain, kabhi bahujan ho jaate hain, bas jan nahi ban pa rahe hain ki jan gan man mein hamari bhi ginati ho jaaye," which literally translates to, "We are so often referred to as Hari's people or people in the majority that we are forgotten as simply people and not counted among those referred to in the national anthem," is heart-wrenching because it is true. We claim to give people from the scheduled castes and tribes (SCs/STs) special status to elevate them, but had we not discriminated against them so far, this special status would not need to be accorded, and they would not need to feel 